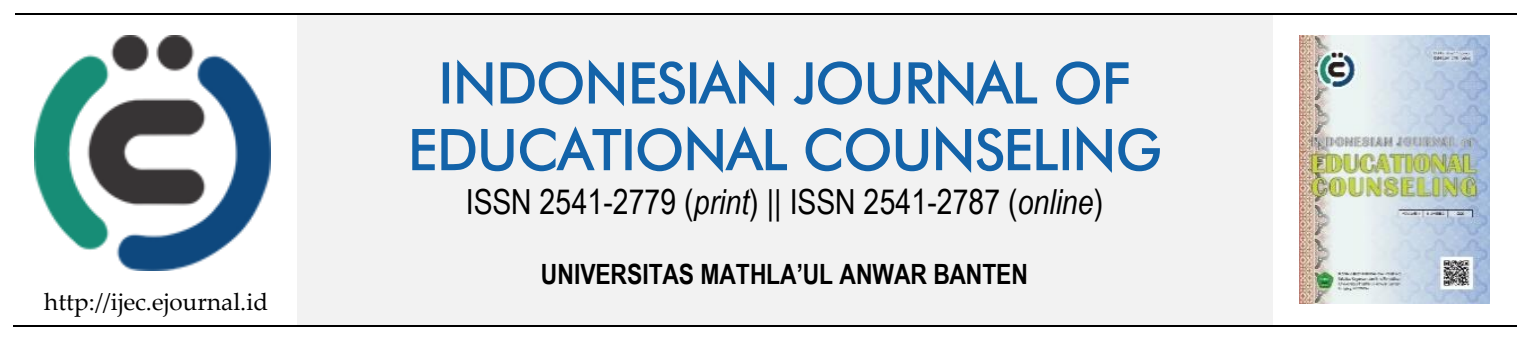

Research Based Article

\title{
Konseling Kelompok Eksistensial untuk Meningkatkan Sense of School Belonging pada Siswa SMK Se-Kota Yogyakarta
}

\author{
Fadhila Malasari Ardini ${ }^{1}$, Aprilia Setyowati ${ }^{2}$, Mufied Fauziah ${ }^{2}$ \\ ${ }^{1}$ Universitas Mathla'ul Anwar Banten, Indonesia, ${ }^{2}$ Universitas Ahmad Dahlan, Indonesia
}

\begin{tabular}{|c|c|}
\hline Article History & ABSTRACT \\
\hline $\begin{array}{l}\text { Received: } 05.02 .2020 \\
\text { Received in revised form: } \\
02.06 .2020 \\
\text { Accepted: } 25.06 .2020 \\
\text { Available online: } 20.07 .2020\end{array}$ & $\begin{array}{l}\text { EXISTENTIAL GROUP COUNSELING TO IMPROVE SENSE OF SCHOOL } \\
\text { BELONGING IN VOCATIONAL SCHOOL STUDENTS IN YOGYAKARTA } \\
\text { CITY. The aim of this study was to develop existential group conseling model } \\
\text { to increase sense of belonging vocational school stundents in Yogyakarta. The } \\
\text { development of group counseling models using an existential approach is one } \\
\text { alternative that can be used to improve the sense of school belonging. The type } \\
\text { of research used is Research and Development model that developed by Borg } \\
\text { and Gall. The research subjects were students of State Vocational Schools in } \\
\text { Yogyakarta who had low sense of school belonging. Data collection techniques } \\
\text { using the sense of school belonging scale adapted from The Psychological Sense } \\
\text { of School Membership (PSSM) Scale, developed by Carol Goodenow. Through } \\
\text { testing the model, it is known that the average posttest score has increased from } \\
42.75 \text { to } 52.75 \text {, meaning that the average value of students' sense of school } \\
\text { belonging has changed by } 10 \text {. As for the minimum value, the pretest scores } \\
\text { obtained the minimum student is } 34.00 \text { in the low category, experiencing a } \\
\text { change in grades when the post-test becomes } 42.00 \text { in the medium category, } \\
\text { meaning that there are no students in the low category. For the maximum score, } \\
\text { which in the pretest the maximum value of the students is } 47.00 \text { in the medium } \\
\text { category, it changes in the score at the post test to be } 65.00 \text { in the high category. }\end{array}$ \\
\hline
\end{tabular}

DOI: $10.30653 / 001.202042 .140$

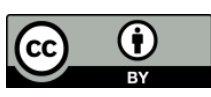

This is an open access article distributed under the terms of the Creative Commons Attribution 4.0 International License, which permits unrestricted use, distribution, and reproduction in any medium, provided the original work is properly cited. (c) 2020 Fadhila Malasari Ardini, Aprilia Setyowati, Mufied Fauziah.

\section{PENDAHULUAN}

Kemajuan suatu bangsa dapat diukur dari berbagai aspek, salah satunya adalah dari aspek pendidikan. Di Indonesia, setiap anak berhak mendapakan layanan pendidikan formal hingga 12 tahun. Selain lingkungan keluarga, lingkungan sekolah merupakan lingkungan belajar yang sangat berpengaruh pada kesuksesan seseorang. Seseorang dapat mencapai kesuksesan di apabila sekolah memberikan layanan dan pengajaran yang tidak hanya berfokus pada aspek akademis siswa, melainkan juga menciptakan

${ }^{1}$ Corresponding author's address: Program Studi Bimbingan dan Konseling FKIP Universitas Mathla'ul Anwar Banten; Jalan Raya Labuan KM 23, Cikaliung, Saketi, Kabupaten Pandeglang, Banten 42273, Indonesia. Email: fadhila.m.a@ gmail.com 
lingkungan emosional yang positif bagi siswanya. Lingkungan emosional yang positif dapat membantu siswa merasa nyaman dan menempatkan dirinya sebagai bagian dari lingkungan sekolah. Lingkungan yang baik dapat terbentuk saat anggotanya mengalami rasa memiliki atau keterikatan (belonging) pribadi (Booker, 2004). Perilaku positif dan produktif siswa dapat tumbuh dan berkembang dengan baik apabila siswa memiliki perasaan diterima secara pribadi, dihormati, dan didukung oleh orang lain di sekolah. Keanggotaan dalam sekolah mengacu pada rasa memiliki atau keanggotaan psikologis siswa di sekolah atau di kelas yang disebut sebagai sense of school belonging (Setyowati \& Fauziah, 2019). Dengan kata lain, sense of school belonging merupakan perasaan dimana siswa merasa terikat dengan sekolah.

Sense of school belonging melibatkan dukungan dan penghormatan terhadap otonomi pribadi dan siswa sebagai individu (Goodenew dalam Setyowati \& Fauziah, 2019). Studi penelitian menunjukkan bahwa sense of school belonging terkait dengan banyak aspek akademis dan pengalaman psikologis dalam pendidikan siswa (Booker, dalam Setyowati \& Fauziah, 2019). Menurut Osterman (2000) siswa yang mengalami penerimaan lebih termotivasi dan terlibat dalam belajar dan lebih berkomitmen pada sekolah. Beck \& Malley (1998) mengungkapkan bahwa siswa dengan sense of school belonging yang tinggi lebih memiliki rasa bernilai dan percaya diri. Sense of belonging yang kuat dapat mempengaruhi siswa dalam berbagai bidang seperti peningkatan semangat mengerjakan tugas, stabilitas emosi yang lebih baik dan tingkat kenakalan yang lebih rendah (McNeely, Nonnemaker, \& Blum, 2002). Sedangkan di Indonesia sendiri, TIMSS (Trends International in Mathematics and Science Study) mengungkapkan hasil pengujian terhadap para siswa di tahun 2011 terungkap bahwa nilai matematika siswa di Indonesia menempati urutan ke 38 dari 42 negara, sedangkan untuk sains menempati urutan ke 40 dari 42 negara (Martin dkk, 2012).

Anderman (2002) menyatakan ada konsensus umum di kalangan peneliti di lapangan bahwa sense of school belonging adalah salah satu kebutuhan psikologis dasar dan ketika kebutuhan ini terpenuhi maka hasil pendidikan positif terjadi. Siswa yang memiliki sense of school belonging yang tinggi menunjukkan perilaku yang mampu menerima norma-norma yang ditetapkan oleh sekolah (McVittie, 2003). Lebih lanjut, sense of school belonging yang dimiliki oleh siswa dapat mengarahkan mereka pada sikap-sikap dan pembelajaran yang lebih positif dan menurunkan perilaku-perilaku negatif di sekolah (Allen \& Bowless dalam Setyowati \& Fauziah, 2019).

Finn (1989) menunjukkan bahwa jika siswa tidak mampu mengidentifikasi dengan baik mengenai sekolah mereka (seperti merasa disambut, dihargai dan dihormati) maka partisipasi siswa dalam pendidikan akan cenderung lemah. Catalano, Haggerty, Oesterle, Fleming, dan Hawkins (2004) mencatat bahwa tingginya tingkat sense of school belonging di Sekolah menengah berkorelasi negatif dengan penyalahgunaan napza, tapi juga menyebabkan rendahnya tingkat masalah akademik, kenakalan remaja, keanggotaan geng, dan aktivitas seksual di luar nikah. Sense of school belonging memiliki pengaruh pada perilaku kekerasan sekolah. Burnett \& Walz (1994) menunjukkan bahwa masalah terkait geng meningkat saat siswa tidak memiliki sense of school belonging pada sekolah mereka. Berdasarkan hasil penelitian Widianto (2008) bentuk-bentuk kenakalan siswa di Kota Yogyakarta meliputi bolos sekolah, merokok, mabuk-mabukan, pesta narkoba, perkelahian, pencurian, pergaulan sex bebas, pemalakan, kebiasaan mengakses situs porno, sering terlambat masuk sekolah, seragam sekolah dan sepatu tidak rapi, kebiasaan mecorat-coret tembok, membawa dan koleksi gambar porno, dan rambut panjang bagi siswa. 
Paparan hasil penelitian menjelaskan bahwa siswa yang merasa terikat dengan sekolah akan lebih memiliki komitmen yang besar dengan sekolah. Data yang diperoleh dari Badan Pusat Statistik Provinsi Yogyakarta menunjukkan Jumlah Murid Putus Sekolah di D.I. Yogyakarta tahun 2015/2016 masih cukup besar, terutama angka putus sekolah tertinggi ada pada tingkat SMK di kota Yogyakarta, yaitu sebanyak 162 siswa putus sekolah. Oleh karena itu, penting bagi sekolah untuk memperhatikan masalah eksistensi atau rasa keterikatan siswa dengan sekolah.

Keterlibatan dalam kegiatan sekolah juga dipandang sebagai cara untuk mengatasi masalah keterasingan siswa dari sekolah (Fredericks, Blumenfeld dan Paris, 2004). Sidorkin (2004) mencatat bahwa sekolah dapat memfasilitasi hubungan antara guru dan siswa dengan merancang "kegiatan" yang disengaja atau tugas pembelajaran otentik yang menurut siswa bermanfaat. Bagaimana hubungan dengan guru merupakan hal yang cukup penting selama masa remaja karena siswa akan cenderung berusaha mencari dukungan dan bimbingan dariorang dewasa di luar rumah (Murray: 2009). Salah satu kegiatan yang dapat dirancang untuk mengatasi minimnya sense of school belonging pada siswa ialah konseling. Konseling bertujuan untuk mengubah kesadaran, memberikan insight mengenai pengembangan potensi dan meningkatkan pengetahuan diri sehingga individu memperoleh motivasi untuk melakukan hal-hal yang benar (Suhendro, 2013).

Pemberian layanan konseling pada siswa juga perlu mempertimbangkan beberapa aspek mengenai karakter siswa sebagai remaja. Masa remaja merupakan masa kritis dalam perkembangan sosial saat individu mulai membutuhkan koneksi interpersonal. Teman merupakan salah satu cara utama dalam memenuhi kebutuhan akan koneksi interpersonal itu (Crosnoe, 2011). Penerimaan oleh teman sebaya di sekolah merupakan faktor penting yang mempengaruhi sense of school belonging (You, Ritchey \& Furlong, 2011). Baumeister \& Leary (1995) mencatat bahwa kebutuhan untuk terikat dan memperoleh penerimaan dari teman sebaya sangatlah besar sehingga individu akan cenderung mencari dan mengembangkan kesempatan untuk menjalin hubungan dengan teman sebaya. Oleh karenanya, konseling kelompok dirasa cocok untuk membantu siswa menumbuhkan sense of school belonging.

Konseling kelompok menurut kemendikbud (2016) merupakan layanan konseling yang diberikan kepada sejumlah peserta didik/konseli dalam suasana kelompok dengan memanfaatkan dinamika kelompok untuk saling belajar dari pengalaman para anggotanya sehingga peserta didik/konseli dapat mengatasi masalah. Layanan konseling berbasis kelompok dirasa cocok diberikan kepada siswa dengan memanfaatkan adanya kecenderungan pada remaja untuk berkelompok dengan teman sebaya.

Salah satu pendekatan konseling yang memandang manusia merupakan makhluk yang mampu memaknai hidup atau eksistensinya di dunia adalah pendekatan konseling eksistensial. Konseling eksistensial berfokus pada perkembangan berlandaskan hal yang positif. Lebih lanjut, konseling eksistensial berfokus pada saat sekarang dan yang akan datang. Konseling eksistensial menyajikan kondisi-kondisi untuk memaksimalkan kesadaran diri dan pertumbuhan, menghapus penghambat dalam mengoptimalkan potensi pribadi. Konseling eksistensial juga membantu siswa agar bebas dan bertanggung jawab atas arah kehidupannya sendiri, May (Corey, 2013). Meskipun demikian, belum dijumpai proses konseling kelompok dengan pendekatan eksistensial untuk meningkatkan tingkat sense of school belonging pada siswa, sehingga penelitian akan diarahkan untuk mengembangkan model konseling kelompok dengan pendekatan eksistensial untuk meningkatkan sense of school belonging siswa. 


\section{METODE}

Jenis penelitian yang digunakan ialah Penelitian dan Pengembangan (Research and Development) menggunakan model yang dikembangkan Borg and Gall. Subyek penelitian merupakan siswa SMK Negeri se-Kota Yogyakarta yang memiliki sense of school belonging rendah. Teknik pengumpulan data menggunakan skala sense of school belonging yang diadaptasi dari The Psychological Sense of School Membership (PSSM) Scale yang dikembangkan oleh Carol Goodenow. Analisis data menggunakan analisis data kualitatif dan kauntitatif. Subyek penelitian berjumlah 193 dari tujuh sekolah SMK Negeri Kota Yogyakarta.

\section{HASIL DAN PEMBAHASAN}

Harison (Kurnanto, 2013) mendefinisikan konseling kelompok sebagai konseling yang terdiri dari 4-8 konseli yang bertemu dengan 1-2 konselor. Dalam proses konseling kelompok dapat membicarakan beberapa masalah, seperti kemampuan dalam membangun hubungan dan komunikasi, pengembangan harga diri, dan keterampilanketerampilan dalam mengatasi masalah. Konseling kelompok bersifat memberikan kemudahan dalam pertumbuhan dan perkebangan individu, dalam arti konseling kelompok memberikan dorongan dan motivasi kepada individu untuk membuat perubahan-perubahan dengan memanfaatkan potensi secara maksimal sehingga dapat mewujudkan diri.

Pendekatan eksistensial humanistik mengembalikan pribadi kepada fokus sentral, memberikan gambaran tentang manusia pada tarafnya yang tertinggi. Ia menunjukkan bahwa manusia selalu ada dalam proses pemenjadian dan bahwa manusia secara sinambung mengaktualkan dan memenuhi potensinya. Pendekatan eksistensial humanistik secara tajam berfokus pada fakta-fakta utama keberadaan manusia, kesadaran diri, dan kebebasan yang konsisten (Corey: 2009). Konsep utama dari pendekatan eksistensial yaitu terdiri dari kesaradan diri, kebebasan, tanggung jawab dan kecemasan, serta penciptaan makna.

Kesadaran diri manusia memiliki kesanggupan untuk menyadari dirinya sendiri, suatu kesanggupan yang unik dan nyata yang memungkinkan manusia mampu berpikir dan memutuskan. Semakin kuat kesadaran diri itu pada seseorang, maka akan semakin besar pula kebebasan yang ada pada orang itu. Kesanggupan untuk memilih alternatifalternatif yakni memutuskan secara bebas di dalam kerangka pembatasnya adalah suatu aspek yang esensial pada manusia.

Kebebasan dan tanggung jawabdapat menimbulkan kecemasan yang menjadi atribut dasar pada manusia. Kecemasan eksistensial juga bisa diakibatkan oleh kesadaran atas keterbatasannya dan atas kemungkinan yang tak terhindarkan untuk mati. Kesadaran atas kematian memiliki arti penting bagi kehidupan individu sekarang, sebab kesadaran tersebut menghadapkan individu pada kenyataan bahwa dia memiliki waktu yang terbatas untuk mengaktualkan potensi-potensinya.

Penciptaan Makna manusia itu unik, dalam artian bahwa dia berusaha untuk menemukan tujuan hidup dan menciptakan nilai-nilai yang akan memberikan makna bagi kehidupan. Pada hakikatnya manusia memiliki kebutuhan untuk berhubungan dengan sesamanya dalam suatu cara yang bermakna, sebab manusia adalah makhluk rasional. Kegagalan dalam menciptakan hubungan yang bermakna dapat menimbulkan 
kondisi-kondisi keterasingan dan kesepian. Manusia juga berusaha untuk mengaktualkan diri yakni mengungkapkan potensi-potensi manusiawinya sampai taraf tertentu.

Model konseling kelompok eksistensial dikembangkan dengan memperhatikan tiga komponen utama yang ada dalam pendekatan eksistensial. Sehingga konseling kelompok eksistensial dapat dimaknai sebagai proses konseling yang dilakukan secara kelompok untuk menyelesaikan permasalahan anggota kelompok dengan memanfaatkan dinamika kelompok berupa berbagi pengalaman dan pendapat dengan mempertimbangkan aspek kesadaran diri; kebebasan, tanggung jawab dan kecemasan; dan penciptaan makna hidup.

Goodenow (1993) menjelaskan bahwa sense of school belonging meliputi beberapa aspek didalamnya, meliputi personal acceptance, perceiving liking, inclusion, respect, dan encouragement for participant. Personal acceptance merupakan keadaan ketika siswa mampu menerima keadaan diri, perceiving liking merupakan keadaan ketika siswa mampu menunjukkan bahwa dirinya disukai oleh teman-teman di sekolah, inclusion merupakaan keadaan ketika Siswa dianggap dan diakui keberadaannya, respect menunjukkan peran untuk dihormati dan menghormati orang di lingkungan sekolah, dan encouragement for participant mengidentifikasi iklim (baik kegiatan maupun personil) di sekolah yang mendorong untuk berpartisipasi di sekolah.

Faircloth \& Hamm (2005) menjelaskan bahwa sense of belonging pada remaja terdiri dari tiga aspek yaitu: (1) Jaringan teman yang positif dimana remaja merasa dikenali (2) hubungan positif dengan guru atau orang dewasa lainnya dimana remaja merasa dihargai, didukung, dan diyakinkan bahwa mereka akan memperoleh bantuan ketika masa-masa sulit, dan (3) berpartisispasi dalam kegiatan ekstrakurikuler, budaya , olah raga atau kegiatan lainnya. Aspek-aspek tersebut menunjukkan orang-orang dan kegiatan yang memiliki pengaruh yang signifikan terhadap siswa selama berada pada lingkungan sekolah.

Wehlage (dalam Togari, dkk., 2011) mengusulkan teori sense of belonging dan school membership yang kemudian oleh Goodenow (dalam Togari, dkk., 2011) digunakan untuk mengembangkan skala Psychological Sense of School Membership untuk mengukur tingkat sense of school belonging siswa. Berdasarkan pengembagan terhadap skala PSSM yang telah dilakukan Togari (2011), skala tersebut tersusun atas tiga faktor yaitu belonging, acceptance by teacher dan acceptance by students. Berdasarkan hasil penelitian yang dilakukan oleh Togari (2011), maka faktor yang mempengaruhi munculnya sense of school belonging pada diri siswa terdiri dari kualitas antara siswa tersebut dengan guru, teman sebaya dan lingkungan sekolahnya. Osterman (2000) menyebutkan bahwa terdapat penelitian yang menghubungkan belonginess atau keterikatan dengan hasil yang signifikan terkait beberapa hal di setting pendidikan, yaitu; (1) perkembangan dasar proses psikologis yang penting bagi kesuksesan siswa, 2) sikap dan motif akademik, 3) sikap-sikap pribadi dan sosial, 4) kewajiban dan partisipasi, serta 5) prestasi akademik.

Hasil penelitian Setyowati \& Fauziah (2019) menunjukkan nilai sense of school belonging pada SMK Negeri di Yogyakarta diketahui urutan sekolah dengan skor ratarata sense of school belonging dari rendah ke tinggi adalah SMKN 5 dengan nilai rata-rata 55,59 yang terdiri dari $22,73 \%$ pada kategori tinggi dan $77,27 \%$ pada kategori sedang. SMKN 2 dengan nilai rata-rata 56,07 yang terdiri dari 66,67\% pada kategori tinggi 70,00\% pada kategori sedang, dan 3,33\% dalam kategori rendah. SMKN 6 dengan nilai rata-rata 56,91 yang terdiri dari $34,38 \%$ pada kategori tinggi, $62,50 \%$ pada kategori sedang, dan $3,12 \%$ dalam kategori rendah. SMKN 3 dengan nilai rata-rata 57,13 yang terdiri dari $21,74 \%$ pada kategori tinggi dan $78,26 \%$ pada kategori sedang., SMKN 1 dengan nilai rata- 
rata 58,57 yang terdiri dari $40 \%$ pada kategori tinggi dan $60 \%$ pada kategori sedang. SMKN 7 dengan nilai rata-rata 58,67 yang terdiri dari 40,74\% pada kategori tinggi dan $59,26 \%$ pada kategori sedang. Sedangkan sekolah dengan nilai sense of school belonging tertinggi adalah SMKN 4 dengan nilai rata-rata 60,76 yang terdiri dari $34,48 \%$ pada kategori tinggi dan $65,52 \%$ pada kategori sedang.

Berdasarkan model yang telah disusun, kemudian dibentuk kelompok kecil untuk menguji model yang telah dikembangkan. Sekolah yang dipilih untuk menguji model adalah SMK Negeri 2 Yogyakarta jurusan TKJ 1 yang memiliki sense of school belonging berada pada katagori rendah dan sedang. SMK Negeri 2 Yogyakarta merupakan sekolah dengan tingkat sense of school belonging terendah ke dua setelah SMK Negeri 5 Yogyakarta. Nilai rata-rata sense of school belonging antara SMKN 2 (dengan nilai rata-rata 56,07) dan SMKN 5 (dengan nilai rata-rata 55,59) terpaut nilai yang cukup kecil yaitu 0,48, namun saat dilihat siswa-siswa dengan nilai sense of school belonging di masing-masing sekolah, SMKN 2 Yogyakarta memiliki jumlah siswa lebih banyak untuk skor terendah sense of school belonging, sehingga Intervensi dilakukan di SMKN 2 Yogyakarta. Tujuan intervensi pada siswa yang memiliki sense of school belonging pada katagori rendah dan sedang ialah untuk melihat keefektifan model konseling kelompok yang akan dikembangkan untuk meningkatkan sense of school belonging.

Uji coba model dilakukan untuk mengetahui kekurangan dan efektifitas model yang telah dikembangkan. Berdasarkan hasil uji coba, diperoleh dua point yang perlu diperbaiki dalam penyusunan model. Pertama, worksheet yang dikembangkan dalam modul perlu diberikan keterangan lebih lengkap mengenai maksud dan tujuan pengisian worksheet dan cara mengisi worksheet tersebut. Kedua, urutan dalam pelaksanaan model perlu diperbaiki pada pertemuan ketiga dan keempat. Pertemuan ketiga dalam model membahas tentang perceiving like dimana siswa diharapkan mampu menunjukkan bahwa dirinya disukai oleh teman-teman di sekolah, dan pertemuan keempat membahas tentang personal acceptance dimana siswa mampu menerima keadaan dirinya. Untuk menjaga energi kelompok dan alur pengembangan sense of school belonging siswa, maka urutan tersebut dirubah sehingga di pertemuan ketiga akan diarahkan agar siswa mampu menerima diri apa adanya dan dilanjutkan dengan mengidentifikasi hal-hal dalam diri yang dirasa disukai oleh orang lain. Pretest dan posttest juga dilakukan dalam melihat apakah ada perbedaan antara sebelum dan sesudah uji coba model. Berdasarkan pretest dan posttest yang telah dilakukan, diperoleh analisis deskriptif sebagai berikut:

Tabel 1. Tingkat Sense of School Belonging Siswa SMK N Kota Yogyakarta

\begin{tabular}{llllll}
\hline & $\mathrm{N}$ & Mean & Std. Deviation & Minimum & Maximum \\
\hline Pretest & 4 & 42.7500 & 6.13052 & 34.00 & 47.00 \\
Posttest & 4 & 52.7500 & 9.74252 & 42.00 & 65.00 \\
\hline
\end{tabular}

Tabel 1 menunjukkan bahwa rata-rata nilai posttest mengalami peningkatan dari nilai 42,75 menjadi 52,75, artinya rata-rata nilai sense of school belonging siswa mengalami perubahan nilai sebanyak 10 . Sedangkan untuk nilai minimum, yang pada pretest diperoleh nilai minimum siswa adalah 34,00 dalam kategori rendah, mengalami perubahan pada nilai saat post test menjadi 42,00 dalam kategori sedang, artinya tidak ada siswa yang berada dalam kategori rendah. Untuk nilai maximum, yang pada pretest diperoleh nilai maximum siswa adalah 47,00 dalam kategori sedang, mengalami perubahan pada nilai saat post test menjadi 65,00 dalam kategori tinggi. 
Berdasarkan hasil masukan secara kualitatif dari siswa diperoleh catatan bahwa konseling kelompok yang dilakukan memberikan nilai manfaat berupa merasa terfasilitasi dengan memberikan wadah untuk berdiskusi sehingga menemukan temanteman dengan masalah yang sama. Model yang dikembangkan membantu siswa untuk menyadari masalah yang dihadapi dan mulai mengkonstruksi kembali mengenai keyakinan atas eksistensi diri siswa di sekolah. Pelaksanaan konseling kelompok dengan pendekatan eksistensial membantu siswa menyadari alasan mengapa siswa merasa tidak diakui keberadaannya di sekolah, dan mencari kekuatan diri siswa dimana sangat diperlukan di sekolah dan menjadi bagian penting dalam perkembangan sekolah. Sense of school belonging yang rendah dari kelompok yang terbentuk diakibatkan karena ketidakmampuan menerima masa lalu (contoh: memilih sekolah dan jurusan karena alasan tidak rasional terkait ikut-ikut teman atau diminta orang tua), merasa tidak dianggap di masa kini (contoh: guru-guru hanya menganggap siswa-siswa yang pintar dan tidak memperhatikan mereka), dan kekhawatiran dengan masa depan (contoh: siswa merasa tidak yakin dapat bekerja melalui apa yang mereka pelajari sekarang).

Model konseling kelompok yang dikembangkan menampung masalah tersebut dan mencoba untuk mengidentifikasi informasi-informasi yang mungkin terlewatkan. Siswa dituntun untuk berdamai dengan diri sendiri dengan berbagai kekurangan dan masalah yang dihadapi, kemudian secara perlahan siswa diajak untuk melihat sisi lain dalam diri terkait dengan kekuatan diri baik yang mereka lihat sendiri maupun dari sudut pandang orang lain. Selain identifikasi diri, model konseling kelompok yang dikembangkan juga memungkinkan siswa untuk mampu mengidentifikasi peluang-peluang yang ada di sekolah yang memberikan kesempatan bagi siswa untuk menunjukkan eksistensi dirinya.

\section{SIMPULAN}

Berdasarkan hasil penelitian dan pembahasan, dapat disimpulkan penyesuaian sosial remaja single sex schools di SMA Daarut Tauhid Bandung Tahun Ajaran 2019/2020 $50 \%$ dengan frekuensi 13 orang termasuk dalam kategori tinggi (well-adjustment), dan 50\% responden dengan frekuensi 13 orang termasuk dalam kategori rendah (maladajustment). Artinya, perlu ada upaya layanan bimbingan dan konseling untuk pengembangan dan perbaikan penyesuaian diri siswa. Layanan pengembangan dapat dilakukan melalui layanan dasar sementara layanan perbaikan penyesuaian diri dapat dilakukan melalui layanan responsif yang disesuaikan dengan kebutuhan peserta didik. Model konseling kelompok yang dikembangkan mengacu pada lima aspek dalam sense of school belonging meliputi personal acceptance, perceiving liking, inclusion, respect, dan encouragement for participant. Melalui uji coba model, diketahui bahwa rata-rata nilai posttest mengalami peningkatan dari nilai 42,75 menjadi 52,75, artinya rata-rata nilai sense of school belonging siswa mengalami perubahan nilai sebanyak 10. Sedangkan untuk nilai minimum, yang pada pretest diperoleh nilai minimum siswa adalah 34,00 dalam kategori rendah, mengalami perubahan pada nilai saat post test menjadi 42,00 dalam kategori sedang, artinya tidak ada siswa yang berada dalam kategori rendah. Untuk nilai maximum, yang pada pretest diperoleh nilai maximum siswa adalah 47,00 dalam kategori sedang, mengalami perubahan pada nilai saat post test menjadi 65,00 dalam kategori tinggi. 


\section{REFERENSI}

Allen, K. A., \& Bowles, T. (2012). Belonging as a Guiding Principle in the Education of Adolescents. Australian Journal of Educational \& Developmental Psychology, 12, 108-119.

Anderman, E. M. (2002). School effects on psychological outcomes during adolescence. Journal of Educational Psychology, 94, 795-809.

Baumeister, R. F., \& Leary, M. R. (1995). The need to belong: Desire for interpersonal attachments as a fundamental human motivation. Psychological Bulletin, 117(3), $497-$ 529.

Beck, M., \& Malley, J. (1998). A pedagogy of belonging. Reclaiming Children and Youth,.7(3), 133-137.

Booker, K. C. (2004). Exploring school belonging and academic achievement in African American adolescents. Curriculum and Teaching Dialogue, 6(2), 131-143.

Catalano, R. F., Haggerty, K. P., Oesterle, S., Fleming, C. B., \& Hawkins, J. D. (2004). The importance of bonding to school for healthy development: Findings from the Social Development Research Group. Journal of School Health, 74, 252-261.

Combs, A. W. (1982). Affective education or none at all. Educational Leadership, 39(7), 495497.

Corey, G. (2013). Teori dan Praktek Konseling \& Psikoterapi. Bandung: Refika Aditama.

Crosnoe, R. (2011). Fitting in, standing out: Navigating the social challenges of high school to get an education. New York: Cambridge University Press.

Faircloth, B. S., \& Hamm, J. V. (2005). Sense of belonging among high school students representing 4 ethnic groups. Journal of Youth and Adolescence, 34(4), 293-309.

Fredericks, J. A., Blumenfeld, P. C., \& Paris, A. H. (2004). School engagement: Potential of the concept, and state of the evidence. Review of Educational Research, 74(1), 59-109.

Fine, M. (1991). Framing dropouts. Albany, NY: SUN Press.

Gall, M. D., Gall, J. P., \& Borg, W. R. (2003). Educational Research, An Introduction. Boston: Pearson Education.

Goodenow, C. (1993). Classroom belonging among early adolescent students: Relationships to motivation and achievement. Journal of Early Adolescence, 13, 21-43.

Kurnanto, E. (2013). Konseling kelompok. Bandung: Alfabeta.

Maslow, A. (1962). Toward a psychology of belonging. Princeton, NJ: Van Nostrand.

McNeely, C. A., Nonnemaker, J. M., \& Blum, R. W. (2002). Promoting school connectedness: Evidence from the national longitudinal study of adolescent health. Journal of School Health, 72(4), 138.-146. 
McVittie. J. (2003). Research Supporting positive discipline in homes, schools, and commite. Atlanta: Positive Discipline Associate.

Murray, C. (2009). Parent and teacher relationships as predictors of school engagement and functioning among low-income urban youth. Journal of Early Adolescent, 29, 376404.

Osterman, K. F. (2000). Students' need for belonging in the school community. Review of Educational Research, 70(3), 323-367.

Rusmana, N. (2009). Bimbingan dan konseling kelompok di sekolah (Metode, teknik dan aplikasi). Bandung: Rizqi Press.

Sidorkin, A. (2004). In the event of learning: Alienation and participative thinking in education. Educational Theory, 54(3), 251-261.

Suhendro, W. (2013). Psikoterapi pada penyakit szizofrenia. E-Jurnal Medika Udayana, 2. 2135-2146.

Sukmadinata, N. S. (2010). Metode penelitian pendidikan. Bandung: Remaja Rosdakarya.

Widianto, A. (2008). Perilaku kenakalan remaja Yogyakarta. Skripsi. Yogyakarta: UIN Yogyakarta.

You, S., Ritchey, K. M., \& Furlong, M. J. (2011). Examination of the latent structure of the psychological sense of school membership scale. Journal of Psychoeducational Assessment, 29(3), 225-237. 